\title{
Comparative Analysis of a Monoclonal Antibody-Based Streptococcus mutans Detection Method with Selective Culture Assays Using Polymerase Chain Reaction as a Gold Standard
}

\author{
FANG GU,,$^{1, *}$ FENGXIA QI, ${ }^{1}$ MAXWELL H. ANDERSON,${ }^{2}$ and WENYUAN SHI ${ }^{1, *}$
}

\begin{abstract}
The aim of this study was to compare a recently developed monoclonal antibody (MAb)-based salivary Streptococcus mutans detection method with various selective media using polymerase chain reaction (PCR) as the gold standard. Salivary $S$. mutans cells were enumerated with a MAb-based method, along with three commonly used selective media, mitis-salivarius-bacitracin agar (MSB), trypticase yeast-extract cystine sucrose bacitracin agar (TYCSB), and glucose-sucrose-potassium tellurite-bacitracin (GSTB) agar. Statistical analysis showed no significant correlations between each method. With PCR as the standard, a MAb-based detection method was found to provide the highest sensitivity $(91 \%)$ and specificity $(96 \%)$ among these four methods. This study demonstrates that the MAb-based detection method may provide more accurate enumeration of salivary $S$. mutans than selective media.
\end{abstract}

\section{INTRODUCTION}

Ince StREPtococcus mutans was first isolated and described $\checkmark$ by Clark in 1924, ${ }^{(1)}$ it has been considered a major cariogenic bacterium involved in the initiation and progression of dental caries. ${ }^{(2-4)}$ The bacterium was found to induce dental caries in human subjects and experimental animals. ${ }^{(2-5)}$ The correlation between $S$. mutans counts in saliva or dental plaque and the incidence of dental caries has been postulated. Various research groups have explored this association. ${ }^{(6-23)}$ Unfortunately, the results have been inconsistent and not conclusive. While some studies found positive associations, ${ }^{(6,9,11,13,15,20-23)}$ others obtained conflicting results. ${ }^{(7,8,10,12,14,16,18,19)}$ There are many variables in the studies that could be responsible for the different results. One of these could be the selective culture method used in these studies to enumerate $S$. mutans. ${ }^{(24)}$ The most commonly used selective medium for $S$. mutans is mitis-salivarius-bacitracin (MSB) agar. ${ }^{(25)}$ The other selective media include trypticase yeast-extract cystine sucrose bacitracin (TYCSB) agar ${ }^{(26)}$ and glucosesucrose-potassium tellurite-bacitracin (GSTB) agar.(27) Because there is no selective medium that allows only one bacterial species to grow, these culture-based methods only provide limited accuracy. ${ }^{(24,28-30)}$ Recently, polymerase chain reaction (PCR)based $^{(31-37)}$ and monoclonal antibody (MAb)-based ${ }^{(38-41)}$ methods have been developed for quantitatively detecting salivary $S$. mutans. Our group had developed a set of MAbs, ${ }^{(41)}$ which can quantitatively and accurately detect species-specific surface antigens of $S$. mutans in saliva and plaques. ${ }^{(39)}$ The MAb-based $S$. mutans detection methods could provide a new opportunity for reexamining the relationship between salivary $S$. mutans counts and caries incidence. However, our previous investigation on application of these MAbs in quantitative detection of $S$. mutans was performed using defined bacterial species. ${ }^{(39,41)}$ The accuracy of this method in detection and quantification of salivary $S$. mutans has not been systematically evaluated. This study aims to analyze the accuracy of the antibody-based detection method that we have developed previously in quantification of salivary $S$. mutans in comparison to commonly used selective media using PCR as the gold standard. The ultimate goal of the study is to identify a reliable way to quantitatively detect salivary $S . m u$ tans, which could potentially serve as an index for caries risk assessment.

\footnotetext{
${ }^{1}$ School of Dentistry and Dental Research Institute, University of California, Los Angeles, California.

${ }^{2} \mathrm{C} 3$ Jian Corporation, Sequim, Washington.

*Current address: School of Dentistry, University of Michigan, Ann Arbor, Michigan.
} 


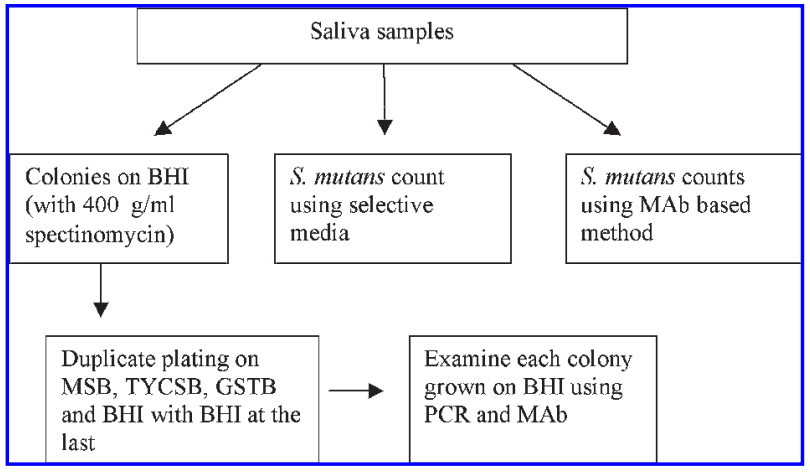

FIG. 1. Research design for this study.

\section{MATERIALS AND METHODS}

\section{Research design}

The research design for comparative analysis was shown in Figure 1. Saliva from each sample was diluted into appropriate concentrations and divided into three parts. One part was cultured on BHI with spectinomycin $(\mathrm{Spc})$ plates ( $\mathrm{Spc}$ was used to eliminate sensitive bacteria from saliva to ease colony counting) to count the total colony forming units (CFUs), which would include $S$. mutans and other species that are resistant to $\mathrm{Spc}$ and can grow on BHI plates. The second part was cultured on selective plates (MSB, TYCSB, GSTB) to select for $S$. mutans. The third part was used for counting $S$. mutans directly under the microscope using MAbs. After colonies appeared on BHI plates, they were serially transferred onto MSB, TYCSB, GSTB, and BHI plates with BHI plates last. The plates were incubated at $37^{\circ} \mathrm{C}$ anaerobically for 3 days. Colonies grown on the selective plates were counted, and colonies grown on BHI plates were used for colony PCR to identify $S$. mutans as well as stained directly with anti-S. mutans MAb. Data collected were used for statistical analysis.

\section{Saliva collection}

One milliliter of stimulated saliva samples was collected by asking participating human subjects to expectorate into sterile disposable plastic cups after the subjects chewed a piece of paraffin wax for 30 seconds. The saliva samples were immediately processed for microbiologic analysis.

\section{Bacterial strains, media, and culture conditions}

Streptococcal species S. mutans (ATCC 25175), S. rattus (ATCC 19645), S. sanguis (ATCC 19295), S. sobrinus (ATCC 33478), and S. gondonii (ATCC 10558), Actinomyces naeslundii (ATCC 12104), Lactobacilli L. casei (ATCC 11578), L. acidophilus (ATCC 4356), L. plantarum (ATCC 14917), and L. salivarius (ATCC 11742), and Porphyromonas gingivalis (ATCC 33277) were grown in brain-heart infusion (BHI, Difco 0037-17, Difco Laboratories, Detroit, MI) medium anaerobically $\left(80 \% \mathrm{~N}_{2}, 10 \% \mathrm{CO}_{2}\right.$, and $\left.10 \% \mathrm{H}_{2}\right)$ at $37^{\circ} \mathrm{C}$. Escherichia coli was grown in Luria-Bertani (LB) medium with aeration or on LB agar plates at $37^{\circ} \mathrm{C}$.

BHI plate and three commonly used selective media plates,
MS Agar (Difco) with bacitracin (MSB), TYCSB, and GSTB, were prepared according to manufacturer's instructions and papers published previously. ${ }^{(26,27)}$ To enrich streptococcal species from whole saliva samples, spectinomycin was added to BHI plates to a final concentration of $400 \mu \mathrm{g} / \mathrm{mL}$ after sterilization. All plates were stored in plastic bags at $4{ }^{\circ} \mathrm{C}$ and used for a period of up to 1 month.

\section{Enumeration of CFUs of saliva on culture plates}

Stimulated saliva samples were diluted to appropriate concentrations and $100 \mu \mathrm{L}$ of the dilutions of the samples were plated on BHI with $\mathrm{Spc}(400 \mu \mathrm{g} / \mathrm{mL})$ or selective plates (MSB, TYCSB, GSTB). The plates were incubated at $37^{\circ} \mathrm{C}$ anaerobically for 3 days and colonies were counted. The assignment of colonies on the selective plates to $S$. mutans was done by colony morphology.

\section{Enumeration of $\mathrm{S}$. mutans using fluorescent $M A b$}

Ten microliters of collected saliva sample or bacterial solution were mixed with $10 \mu \mathrm{L}$ of culture supernatant of a hybridoma cell line producing an anti-S. mutans MAb, SWLA (about $10 \mu \mathrm{g}$ antibody per milliliter), ${ }^{(39,41)}$ and incubated at room temperature for 30 minutes. One microliter of fluorescein isothiocyanate (FITC)-conjugated goat anti-mouse immunoglobulin $\mathrm{G}(\mathrm{IgG})$ was mixed with the saliva-MAb mixture and incubated at room temperature for 30 minutes. The mixture was then examined using fluorescent microscopy. ${ }^{(39)}$ The number of fluorescent cells within six random observational microscopic fields was counted to reduce the variation. The corresponding colony forming unit per milliliter $(\mathrm{CFU} / \mathrm{mL})$ was calculated using a standard curve.

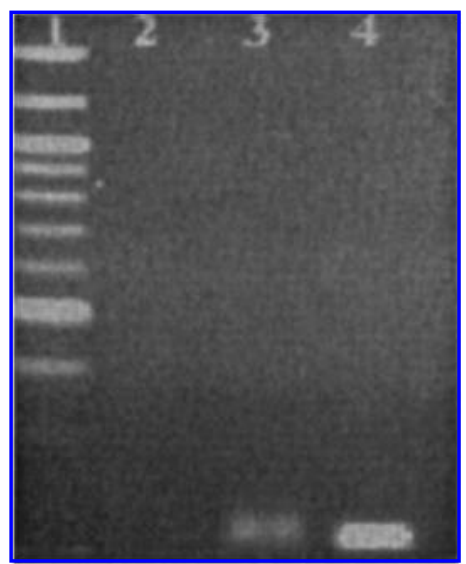

FIG. 2. The specificity of Streptococcus mutans-specific primers. Picture of gel electrophoresis of product from polymerase chain reaction (PCR) using the condition described in Materials and Methods. Lane 1 is DNA ladder. Lane 2 is the product from PCR using the mixture of DNA extracted from $S$. rattus, S. sanguis, S. critatus, S. sobrinus, S. oralis, $S$. gondonii, Actinomyces naeslundii, A. viscosus, Lactobacilli casei, $L$. acidophilus as the template. Lane 3 is the product from PCR using the same bacteria mixture and DNA of $S$. mutans as the template. Lane 4 is product from PCR using DNA of $S$. mutans only as the template. The specific PCR product is $134 \mathrm{bp}$. 
Table 1. Number of Streptococcus mutans in FifteEn Saliva Samples Detected by Different Methods

Salivary S. mutans concentration $\left(10^{5} / \mathrm{mL}\right)$

\begin{tabular}{lrrrr}
\cline { 2 - 5 } Sample no. & MAb & MSB & TYCSB & GSTB \\
\hline 1 & 3 & 0.4 & 0.5 & 0.2 \\
2 & 12 & 22 & 4.3 & 0.1 \\
3 & 42 & 26 & 10 & 0.1 \\
4 & 26 & 0.2 & 0.4 & 0.1 \\
5 & 12 & 0.1 & 20 & 0 \\
6 & 10 & 20 & 19 & 0.1 \\
7 & 12 & 20 & 20 & 0.2 \\
8 & 8 & 3 & 4 & 4 \\
9 & 7 & 8 & 5 & 1 \\
10 & 9 & 4 & 6 & 5 \\
11 & 21 & 4 & 15 & 10 \\
12 & 15 & 7 & 12 & 8 \\
13 & 16 & 7 & 12 & 10 \\
14 & 8 & 5 & 7 & 6 \\
15 & 22 & 4 & 10 & 14 \\
Mean & 14.87 & 8.71 & 9.68 & 3.92 \\
\hline
\end{tabular}

MAb, monoclonal antibody; MSB, mitis-salvarius-bacitracin agar; TYCSB, trypticase yeast-extract cystine sucrose bacitracin agar; GSTB, glucose-sucrose-potassium tellurite bacitracin agar.

The standard curve was established as follows: overnight culture of $S$. mutans was ten-fold serially diluted, and $100 \mu \mathrm{L}$ of the various dilutions were plated on BHI plates. The plates were incubated for 3 days under anaerobic conditions and colonies were counted, which was converted to CFU/mL. Concurrently, $10 \mu \mathrm{L}$ of cell suspension from each dilution was labeled with $\mathrm{MAb}$ and the number of fluorescent cells counted as described above. The standard curve was generated using regression analysis with the number of fluorescent bacteria as the dependent variable and the logarithmic CFU as independent variables. The standard curve was created each time of sample processing to control random variations.

\section{DNA extraction and PCR}

DNA was extracted by mechanical disruption using a homogenizer (Omni International, Inc., Marietta, GA) for $30 \mathrm{sec}-$

Table 2. Correlations Between Different Detection Methods for Salivary Streptococcus mutans

\begin{tabular}{|c|c|c|c|c|}
\hline $\begin{array}{l}\text { Detection } \\
\text { methods }\end{array}$ & $M A b$ & $M S B$ & TYCSB & GSTB \\
\hline MAb & 1 & & & \\
\hline \multirow[t]{2}{*}{ MSB } & 0.34 & & & \\
\hline & $(p=0.21)$ & 1 & & \\
\hline \multirow[t]{2}{*}{ TTCSB } & 0.09 & 0.31 & & \\
\hline & $(p=0.76)$ & $(p=0.26)$ & 1 & \\
\hline GSTB & $\begin{array}{c}0.11 \\
(p=0.71)\end{array}$ & $\begin{array}{c}-0.37 \\
(p=0.18)\end{array}$ & $\begin{array}{c}0.09 \\
(p=0.761)\end{array}$ & 1 \\
\hline
\end{tabular}

MAb, monoclonal antibody; MSB, mitis-salvarius-bacitracin agar; TYCSB, trypticase yeast-extract cystine sucrose bacitracin agar; GSTB, glucose-sucrose-potassium tellurite bacitracin agar. onds, and further purification by phenol-chloroform extraction. The purified DNA of each sample was ethanol precipitated and resuspended in $30 \mu \mathrm{L}$ TE buffer (Tris-ethylenediaminetetraacetic acid [EDTA], pH 7). For PCR, DNA was diluted to a suitable concentration and $1 \mu \mathrm{L}$ was used for each PCR

Table 3. List of Data from Comparative Analysis Using MAb Selective Media

\begin{tabular}{|c|c|c|c|c|c|}
\hline \multirow[b]{2}{*}{ Sample no. } & \multicolumn{5}{|c|}{ Number of colonies } \\
\hline & Test results & $M A b$ & $M S B$ & TYCSB & GSTB \\
\hline \multirow[t]{4}{*}{1} & $\mathrm{TP}^{\mathrm{a}}$ & 1 & 0 & 0 & 0 \\
\hline & $\mathrm{TN}^{\mathrm{b}}$ & 73 & 65 & 64 & 64 \\
\hline & $\mathrm{FN}^{\mathrm{c}}$ & 0 & 1 & 1 & 1 \\
\hline & $\mathrm{FP}^{\mathrm{d}}$ & 0 & 8 & 9 & 9 \\
\hline \multirow[t]{4}{*}{2} & $\mathrm{TP}^{\mathrm{a}}$ & 4 & 1 & 1 & 1 \\
\hline & $\mathrm{TN}^{\mathrm{b}}$ & 114 & 103 & 110 & 111 \\
\hline & $\mathrm{FN}^{\mathrm{c}}$ & 0 & 3 & 3 & 3 \\
\hline & $\mathrm{FP}^{\mathrm{d}}$ & 0 & 11 & 4 & 3 \\
\hline \multirow[t]{4}{*}{3} & $\mathrm{TP}^{\mathrm{a}}$ & 4 & 2 & 0 & 0 \\
\hline & $\mathrm{TN}^{\mathrm{b}}$ & 177 & 119 & 174 & 177 \\
\hline & $\mathrm{FN}^{\mathrm{c}}$ & 0 & 2 & 4 & 4 \\
\hline & $\mathrm{FP}^{\mathrm{d}}$ & 0 & 58 & 3 & 0 \\
\hline \multirow[t]{4}{*}{4} & $\mathrm{TP}^{\mathrm{a}}$ & 29 & 21 & 23 & 20 \\
\hline & $\mathrm{TN}^{\mathrm{b}}$ & 160 & 55 & 59 & 80 \\
\hline & $\mathrm{FN}^{\mathrm{c}}$ & 4 & 11 & 13 & 13 \\
\hline & $\mathrm{FP}^{\mathrm{d}}$ & 2 & 108 & 100 & 82 \\
\hline \multirow[t]{4}{*}{5} & $\mathrm{TP}^{\mathrm{a}}$ & 15 & 15 & 4 & 3 \\
\hline & $\mathrm{TN}^{\mathrm{b}}$ & 11 & 7 & 9 & 12 \\
\hline & $\mathrm{FN}^{\mathrm{c}}$ & 2 & 2 & 13 & 14 \\
\hline & $\mathrm{FP}^{\mathrm{d}}$ & 2 & 6 & 4 & 1 \\
\hline \multirow[t]{4}{*}{6} & $\mathrm{TP}^{\mathrm{a}}$ & 44 & 53 & 47 & 53 \\
\hline & $\mathrm{TN}^{\mathrm{b}}$ & 55 & 3 & 17 & 2 \\
\hline & $\mathrm{FN}^{\mathrm{c}}$ & 4 & 0 & 6 & 0 \\
\hline & $\mathrm{FP}^{\mathrm{d}}$ & 6 & 58 & 44 & 59 \\
\hline \multirow[t]{4}{*}{7} & $\mathrm{TP}^{\mathrm{a}}$ & 6 & 5 & 0 & 6 \\
\hline & $\mathrm{TN}^{\mathrm{b}}$ & 44 & 6 & 35 & 0 \\
\hline & $\mathrm{FN}^{\mathrm{c}}$ & 1 & 2 & 7 & 1 \\
\hline & $\mathrm{FP}^{\mathrm{d}}$ & 0 & 38 & 10 & 44 \\
\hline \multirow[t]{4}{*}{8} & $\mathrm{TP}^{\mathrm{a}}$ & 4 & 1 & 0 & 0 \\
\hline & $\mathrm{TN}^{\mathrm{b}}$ & 68 & 67 & 74 & 72 \\
\hline & $\mathrm{FN}^{\mathrm{c}}$ & 1 & 5 & 5 & 5 \\
\hline & $\mathrm{FP}^{\mathrm{d}}$ & 6 & 6 & 0 & 2 \\
\hline \multirow[t]{4}{*}{9} & $\mathrm{TP}^{\mathrm{a}}$ & 63 & 42 & 55 & 22 \\
\hline & $\mathrm{TN}^{\mathrm{b}}$ & 114 & 79 & 86 & 82 \\
\hline & $\mathrm{FN}^{\mathrm{c}}$ & 6 & 27 & 34 & 70 \\
\hline & $\mathrm{FP}^{\mathrm{d}}$ & 5 & 40 & 13 & 1 \\
\hline
\end{tabular}

${ }^{a} \mathrm{TP}$ (true-positive) is defined as colonies grown on BHI plate that are PCR positive with Streptococcus mutans-specific primers as well as positive with MAb or other culture methods.

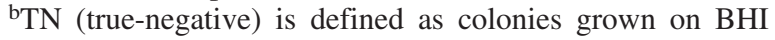
plate that are PCR negative with $S$. mutans-specific primers as well as negative with MAb or other culture methods.

${ }^{\mathrm{c}} \mathrm{FN}$ (false-negative) is defined as colonies grown on BHI plate that are PCR positive with $S$. mutans-specific primers but negative with MAb or other culture methods.

${ }^{\mathrm{d}} \mathrm{FP}$ (false-positive) is defined as colonies grown on BHI plate that are PCR negative with $S$. mutans-specific primers but positive with $\mathrm{MAb}$ or other culture methods.

$\mathrm{MAb}$, monoclonal antibody; MSB, mitis-salvarius-bacitracin agar; TYCSB, trypticase yeast-extract cystine sucrose bacitracin agar; GSTB, glucose-sucrose-potassium tellurite bacitracin agar; PCR, polymerase chain reaction. 
reaction. Two sets of primers were used for PCR. BA968F/ BA1401R (5'-AACGCGAAGAACCTTAC-3'/5'CGGTGTGTACAAGACCC- $\left.3^{\prime}\right)^{(42)}$ amplifies $16 \mathrm{~S}$ DNA of all eubacteria, and SmF205 (5'-ATTCCCTACTGCTGCCTCCC-3') and SmR336 (5'-ATTCCCTACTGCTGCCTCCC-3') amplifies only $S$. mutans $16 \mathrm{~S}$ rDNA. The PCR mix $(50 \mu \mathrm{L})$ contained 0.1 to $1 \mathrm{ng}$ of template DNA, $1 \mathrm{mM} \mathrm{MgCl} 2,5 \%$ (vol/vol) dimethyl sulfoxide (DMSO), $0.1 \mathrm{mM}$ concentrations of each deoxynucleoside triphosphate, $0.4 \mu \mathrm{M}$ concentrations of each primer, $1 \mathrm{U}$ of Taq Polymerase, and TAQ buffer (Promega, Madison, WI), with final concentrations of $10 \mathrm{mM}$ Tris- $\mathrm{HCl}$ (pH 8.3) and $10 \mathrm{mM} \mathrm{KCl}$. Amplification conditions were initial denaturation at $94^{\circ} \mathrm{C}$ for 4 minutes, 30 cycles consisting of denaturation at $94^{\circ} \mathrm{C}$ for 30 seconds, annealing at $55^{\circ} \mathrm{C}$ for 30 seconds, and extension at $72^{\circ} \mathrm{C}$ for 30 seconds, and final extension at $72^{\circ} \mathrm{C}$ for 7 minutes. For colony PCR, a single colony was used as template. The PCR mixture was treated at $95^{\circ} \mathrm{C}$ for 10 minutes before the application of the above amplification conditions.

\section{Statistical analysis}

The number of $S$. mutans was considered as continuous variable that follows normal distribution. Comparisons of the number of $S$. mutans detected with different methods were done with two-way analysis of variance (ANOVA). Pearson correlation analysis was also performed. Comparisons of the sensitivity, specificity, false-negative rate, and false-positive rate were done with one-way ANOVA. For multigroup comparisons, Bonferroni test was applied. Data analysis was performed using version 9.02 of SAS software (SAS Institute, Cary, NC). All statistical tests were two-tailed with a type I error of 0.05 .

\section{RESULTS}

\section{Number of S. mutans in saliva samples detected with} different methods

The number of $S$. mutans from 15 saliva samples was obtained using MAb-based detection method and selective media, MSB, TYCSB, and GSTB, as described in Materials and Methods. The results are presented in Table 1 . The mean of salivary S. mutans counts for these 15 subjects was in the order of
MAb $>$ TYCSB $>$ MSB $>$ GSTB, although the order varies for individual samples. Statistical analysis was performed using Proc ANOVA procedure in SAS (version 9.02). The results showed that there are statistically significant differences in the numbers of salivary $S$. mutans obtained with different methods $(p=0.001)$. The multigroup comparison analysis using Bonferroni test showed that the number of $S$. mutans obtained by MAb-based detection method is statistically significantly higher than the one provided by the GSTB method. The correlations in the numbers of salivary $S$. mutans between different detection methods were analyzed using Proc Corr procedure in SAS (version 9.02) and the correlation coefficiencies along with the associated $p$ value are listed in Table 2. There are no statistically significant correlations between the different methods, suggesting that data obtained in different studies using different $S$. mutans detection methods are not comparable.

\section{Comparative analysis of different detection methods}

As shown above, there is no significant correlation in the number of salivary $S$. mutans between different detection methods. This suggests that some $S$. mutans may not grow on the selective media, while colonies that grew on selective media may not be $S$. mutans. To compare these methods further, we used PCR to test the $S$. mutans specificity of each method. Saliva samples from 9 of the 15 subjects were used in this analysis. As described in Materials and Methods, two sets of primers were used, one set detects $S$. mutans only, and the other set detects all bacteria. As shown in the experimental design (Fig. 1), each colony grown on a BHI plate was examined by PCR as well as $\mathrm{MAb}$. To test the specificity of the $S$. mutans-specific primer, DNA was extracted from $S$. rattus, $S$. sanguis, $S$. sobrinus, $S$. gondonii, Actinomyces naeslundii, Lactobacillus casei, L. acidophilus, L. plantarum, L. salivarius, Porphyromonas gingivalis, and E. coli as described in Materials and Methods. A mixture of DNA extracted from the above organisms was used as template with or without the addition of $S$. mutans DNA. Only samples with $S$. mutans DNA were amplified, indicating that the S. mutans-specific primers are indeed species-specific (Fig. 2).

The specificity of this MAb for $S$. mutans has been reported previously. ${ }^{(39,41)}$ Every colony on BHI plate was examined with MAbs. In cases in which the colony appeared to be a mixture of bacteria, the colony was considered as $S$. mutans positive if more than $50 \%$ of bacterial cells were labeled with the anti-

Table 4. Summary of Diagnostic Value of Different Methods

\begin{tabular}{lcccc}
\hline Method & Sensitivity $^{\mathrm{a}}$ & Specificity $^{\mathrm{b}}$ & False-negative rate $^{\mathrm{c}}$ & False-positive rate $^{\mathrm{d}}$ \\
\hline MAb & $0.91 \pm 0.08$ & $0.96 \pm 0.06$ & $0.07 \pm 0.08$ & $0.04 \pm 0.06$ \\
MSB & $0.53 \pm 0.33$ & $0.57 \pm 0.33$ & $0.48 \pm 0.32$ & $0.43 \pm 0.33$ \\
TYCSB & $0.29 \pm 0.34$ & $0.76 \pm 0.27$ & $0.70 \pm 0.37$ & $0.24 \pm 0.27$ \\
GSTB & $0.35 \pm 0.38$ & $0.68 \pm 0.41$ & $0.73 \pm 0.31$ & $0.32 \pm 0.41$ \\
\hline
\end{tabular}

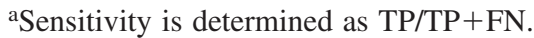

${ }^{\mathrm{b}}$ Specificity is determined as TN/TN $+\mathrm{FP}$.

${ }^{c}$ False negative rate is calculated as $\mathrm{FN} / \mathrm{TP}+\mathrm{FN}$.

${ }^{\mathrm{d}}$ False positive rate is calculated as $\mathrm{FP} / \mathrm{FP}+\mathrm{TN}$.

$\mathrm{MAb}$, monoclonal antibody; MSB, mitis-salvarius-bacitracin agar; TYCSB, trypticase yeast-extract cystine sucrose bacitracin agar; GSTB, glucose-sucrose-potassium tellurite bacitracin agar; TP, true-positive; FN, false-negative; TN, true-negative; FP, false-positive. 
body. The results of this comparative analysis are listed in Table 3. The calculations of sensitivity, specificity, false-positive rate, and false-negative rate of these methods are illustrated in Table 4. As shown in Tables 3 and 4, MAb-based detection method shows the highest sensitivity $(90 \%)$, followed by selective medium MSB (53\%), GSTB (35\%), and TYCSB (29\%). The MAb-based detection method also shows the highest specificity (96\%) followed by TYCBS (76\%), GSTB (68\%), and MSB $(57 \%)$. The differences in the sensitivities and specificities of these detection methods were analyzed using Proc ANOVA procedure in statistical software, SAS (version 9.02). There is a statistically significant difference in sensitivities between different methods $(p=0.0007)$. There are also statistically significant differences in false-negative $(p=0.0001)$ and falsepositive rates $(p=0.0001)$. Unexpectedly, the differences in specificity between different methods are not statistically significantly different $(p=0.057)$, probably due to large variations and small sample size.

\section{DISCUSSION}

Dental caries is a prevalent chronic infectious disease. Despite the established role of $S$. mutans as the primary pathogen for dental caries, the diagnosis of dental caries is still mainly through nonmicrobiologic methods. ${ }^{(43,44)}$ Previous studies on the association between the levels or proportions of $S$. mutans in saliva or dental plaque and the incidence of dental caries used conventional culture methods with different selective media to detect $S$. mutans. ${ }^{(6-23)}$ These studies resulted in inconsistent, sometimes confusing, and conflicting results. To clarify some of the confusing issues and find a more accurate way for $S$. mutans detection, in this study we systematically compared the MAb-based method that we have established previously with three commonly used selective media based assays. We show that the different selective media as well as MAb-based methods have no correlation with each other in $S$. mutans detection, which may partially explain why conflicting results were obtained in previous studies from different groups.

Using PCR as the gold standard, we compared the accuracy of our MAb-based detection method and commonly used selective media for quantification of salivary S. mutans. Sensitivity, specificity, false-positive, and false-negative rates were calculated for each method. Overall, the MAb-based detection method showed significantly higher sensitivity, lower false-positive rate, and lower false-negative rate than conventional selective culture media (Tables 1-4). Although the specificity between different methods is not statistically different due to large variations in the data set of the selective culture methods, in reality, the MAb-based method is highly likely to have higher specificity than the culture methods, as demonstrated by its much lower false-positive rate. It is also worth noting that compared to the culture-based methods, the MAb-based method gives much smaller standard deviation in all four data sets (specificity, sensitivity, false-positive rate, and false-negative rate). This suggests that culture-based methods are more sensitive to variations in physiologic properties between different strains, while the MAb-based method is more robust probably due to its binding to a common surface antigen present in most, if not all, S. mutans strains. This may also explain the significantly higher number of $S$. mutans detected with the MAb methods than with selective culture methods from the same saliva samples (Table 1).

In addition to being more accurate, MAb-based detection is faster than selective culture assay. It requires only minutes while culture methods take days to see the results. Furthermore, samples for MAb-based analysis can be fixed, making transportation of samples more flexible, while culture based methods require live samples, which limits sample collection and processing only to microbiologic laboratories. These features make the MAb-based $S$. mutans detection a promising vehicle for future dental caries diagnosis. The drawback with the MAb-based detection technique is the cost of producing MAbs. However, with the advancement of MAb techniques, MAbs can now be produced in large quantity at relative low cost.

There are some limitations of this study. As mentioned in the Results section, the sample size was small, which generated large variations especially with the selective culture methods. Furthermore, in order to detect low numbers of $S$. mutans from saliva, a BHI plate with $400 \mu \mathrm{g} / \mathrm{mL}$ of spectinomycin was used. Previous studies have shown that $S$. mutans and other streptococci are resistant to as much as $500 \mu \mathrm{g} / \mathrm{mL}$ of spectinomycin (Qi et al., unpublished data). Although accurate estimates of $S$. mutans concentration $(\mathrm{CFU} / \mathrm{mL})$ can be obtained under this condition, the portion of $S$. mutans relative to other species present in saliva is overestimated. Nonetheless, since the number of $S$. mutans is what the tested methods were designed to detect, the proportion of $S$. mutans in the saliva population becomes irrelevant.

\section{ACKNOWLEDGMENT}

This work was supported in part by National Institutes of Health grant R01-DE014757 to F. Qi and a Delta Dental grant WDS78956 to W. Shi.

\section{REFERENCES}

1. Clark J: On the bacterial factors in the etiology of dental caries. $\mathrm{Br}$ J Exp Pathol 1924;5:141-147.

2. Fitzgerald RJ and Keyes PH: Demonstration of the etiologic role of streptococci in experimental caries in the hamster. $\underline{\mathrm{J} \text { Am Dent }}$ Assoc 1960;61:9-19.

3. Gibbons RJ: Bacteriology of dental caries. J Dent Res 1964; 43(suppl):1021-1028.

4. Loesche WJ: Role of Streptococcus mutans in human dental decay. Microbiol Rev 1986;50:353-380.

5. Hamada S and Slade HD: Biology, immunology, and cariogenicity of Streptococcus mutans. Microbiol Rev 1980;44:331-384.

6. Ansai T, Tahara A, Ikeda M, Katoh Y, Miyazaki H, and Takehara $\mathrm{T}$ : Influence of colonization with mutans streptococci on caries risk in Japanese preschool children: 24 month survival analysis. Pediatric Dent 2000;22:377-380.

7. Boyar RM, Thylstrup A, Holmen L, and Bowden GH: The microflora associated with the development of initial enamel decalcification below orthodontic bands in vivo in children living in a fluoridated-water area. J Dent Res 1989;68:1734-1738.

8. Carlsson P, Gandour IA, Olsson B, Rickardsson B, and Abbas K: High prevalence of mutans streptococci in a population with ex- 
tremely low prevalence of dental caries. Oral Microbiol Immunol 1987;2:121-124.

9. Ellen RP, Banting DW, and Fillery ED: Streptococcus mutans and Lactobacillus detection in the assessment of dental root surface caries risk. J Dent Res 1985;64:1245-1249.

10. Hardie JM, Thomson PL, South RJ, Marsh PD, Bowden GH, McKee AS, Fillery ED, and Slack GL: A longitudinal epidemiological study on dental plaque and the development of dental cariesInterim results after two years. J Dent Res 1977;56(Spec No):C90-98.

11. Holbrook WP, de Soet JJ, and de Graaff J: Prediction of dental caries in pre-school children. Caries Res 1993;27:424-430.

12. Ikeda T, Sandham HJ, and Bradley EL Jr: Changes in Streptococcus mutans and lactobacilli in plaque in relation to the initiation of dental caries in Negro children. Arch Oral Biol 1973;18:555-566.

13. Kohler B, Bjarnason S, Care R, Mackevica I, and Rence I: Mutans streptococci and dental caries prevalence in a group of Latvian preschool children. Eur J Oral Sci 1995;103:264-266.

14. Kristoffersson K, Axelsson P, Birkhed D, and Bratthall D: Caries prevalence, salivary Streptococcus mutans and dietary scores in 13year-old Swedish schoolchildren. Commun Dent Oral Epidem 1986;14:202-205.

15. Kristoffersson K, Grondahl HG, and Bratthall D: The more Streptococcus mutans, the more caries on approximal surfaces. J Dent Res 1985;64:58-61.

16. Lang NP, Hotz PR, Gusberti FA, and Joss A: Longitudinal clinical and microbiological study on the relationship between infection with Streptococcus mutans and the development of caries in humans. Oral Microbiol Immunol 1987;2:39-47.

17. Loesche WJ, Rowan J, Straffon LH, and Loos PJ: Association of Streptococcus mutants with human dental decay. Infect Immun 1975;11:1252-1260.

18. Loesche WJ and Straffon LH: Longitudinal investigation of the role of Streptococcus mutans in human fissure decay. Infect Immun 1979;26:498-507.

19. Milnes AR and Bowden GH: The microflora associated with developing lesions of nursing caries. Caries Res 1985;19:289-297.

20. Thibodeau EA and O'Sullivan DM: Salivary mutans streptococci and incidence of caries in preschool children. Caries Res 1995; 29:148-153.

21. Toi CS, Cleaton-Jones PE, and Daya NP: Mutans streptococci and other caries-associated acidogenic bacteria in five-year-old children in South Africa. Oral Microbiol Immunol 1999;14:238-243.

22. Thibodeau EA and O'Sullivan DM: Salivary mutans streptococci and dental caries patterns in pre-school children. Commun Dent Oral Epidem 1996;24:164-168.

23. Thibodeau EA, O'Sullivan DM, and Tinanoff N: Mutans streptococci and caries prevalence in preschool children. Commun Dent Oral Epidem 1993;21:288-291.

24. Dasanayake AP, Caufield PW, Cutter GR, Roseman JM, and Kohler B: Differences in the detection and enumeration of mutans streptococci due to differences in methods. Arch Oral Biol 1995; 40:345-351.

25. Gold OJ and Van Houte HVJ: A selective medium for Streptococcus mutans. Arch Oral Biol 1973;18:1357-1364.

26. Van Palenstein Helderman W, Ijsseldijk M, and Huis in 't Veld $\mathrm{JH}$ : A selective medium for the two major subgroups of the bacterium Streptococcus mutans isolated from human dental plaque and saliva. Arch Oral Biol 1983;28:599-603.

27. Tanzer JB, Laskowski AC, Kurasz L, and Testa ABM: Glucosesucrose-potassium tellurite-bacitracin agar, an alternative to mitis salivarius-bacitracin agar for enumeration of Streptococcus mutans. J Clin Microbiol 1984;20:653-659.

28. Little WA, Korts DC, Thomson LA, and Bowen WH: Comparative recovery of Streptococcus mutans on ten isolation media. J Clin Microbiol 1977;5:578-583.
29. Schaeken MJ, van der Hoeven JS, and Franken HC: Comparative recovery of Streptococcus mutans on five isolation media, including a new simple selective medium. J Den Res 1986;65:906-908.

30. Svanberg M and Krasse B: Comparative recovery of mutans streptococci on two selective media. Caries Res 1990;24:36-38.

31. Al-Robaiy S, Rupf S, and Eschrich K: Rapid competitive PCR using melting curve analysis for DNA quantification. BioTechniques 2001;31:1382-1386, 1388.

32. Igarashi T, Yamamoto A, and Goto N: Direct detection of Streptococcus mutans in human dental plaque by polymerase chain reaction. Oral Microbiol Immunol 1996;11:294-298.

33. Okada M, Soda Y, Hayashi F, Doi T, Suzuki J, Miura K, and Kozai K: PCR detection of Streptococcus mutans and S. sobrinus in dental plaque samples from Japanese pre-school children. J Med Microb 2002;51:443-447.

34. Rupf S, Kneist S, Merte K, and Eschrich K: Quantitative determination of Streptococcus mutans by using competitive polymerase chain reaction. Eur J Oral Sci 1999;107:75-81.

35. Wang J, Li C, Xiao B, and Liu J: Detection of cariogenic Streptococcus mutans by quantitative polymerase chain reaction. Zhonghua Kou Qiang Yi Xue Za Zhi 2002;37:281-283.

36. Yano A, Kaneko N, Ida H, Yamaguchi T, and Hanada N: Realtime PCR for quantification of Streptococcus mutans. FEMS Microbiol Lett 2002;217:23-30.

37. Yoshida A, Suzuki N, Nakano Y, Kawada M, Oho T, and Koga T: Development of a 5' nuclease-based real-time PCR assay for quantitative detection of cariogenic dental pathogens Streptococcus mutans and Streptococcus sobrinus. J Clin Microbiol 2003; 41:4438-4441.

38. de Soet JJ, van Dalen PJ, Russell RR, and de Graaff J: Identification of mutans streptococci with monoclonal antibodies. Antonie Van Leeuwenhoek 1990;58:219-225.

39. Gu F, Lux R, Anderson MH, del Aguila MA, Wolinsky L, Hume WR, and Shi W: Analyses of Streptococcus mutans in saliva with species-specific monoclonal antibodies. Hybridoma 2002;21: 225-232.

40. Matsumoto Y, Sugihara N, Koseki M, and Maki Y: A rapid and quantitative detection system for Streptococcus mutans in saliva using monoclonal antibodies. Caries Res 2006;40:15-19.

41. Shi W, Jewett A, and Hume WR: Rapid and quantitative detection of Streptococcus mutans with species-specific monoclonal antibodies. Hybridoma 1998;17:365-371.

42. Nubel U, Engelen B, Felske A, Snaidr J, Wieshuber A, Amann RI, Ludwig W, and Backhaus H: Sequence heterogeneities of genes encoding 16S rRNAs in Paenibacillus polymyxa detected by temperature gradient gel electrophoresis. J Bacteriol 1996;178:56365643.

43. Pretty IA and Maupome G: A closer look at diagnosis in clinical dental practice: Part 5. Emerging technologies for caries detection and diagnosis. J Can Dent Assoc 2004;70:540, 540a-540i.

44. Pretty IA and Maupome G: A closer look at diagnosis in clinical dental practice: Part 1 . Reliability, validity, specificity and sensitivity of diagnostic procedures. J Can Dent Assoc 2004;70: 251-255.

Address reprint requests to: Wenyuan Shi, Ph.D. UCLA School of Dentistry 10833 Le Conte Avenue Los Angeles, CA 90095-1668

E-mail: wenyuan@ucla.edu

Received for publication June 13, 2006. Accepted for publication August 9, 2006. 